\title{
Teknik Squat dan Stoop Menggunakan Electromyography pada Pekerjaan Manual Materials Handling
}

\author{
I Wayan Surata ${ }^{1 *}$
}

\begin{abstract}
Manual materials handling has been identified as the most common cause of workrelated musculoskeletal disorders. Among the manual material handling activities, lifting has long been regarded as an activity associated with a high risk of low-back pain. Lifting studies have mainly focused on the squat and stoop lifting techniques as an effort to improve the protection of workers from low back discomfort. However, neither is ideal and the benefits of one technique over another have proved inconclusive. The purpose of this study was to examine and compare the squat and stoop lifting techniques through analysis of muscles activation by using electromyography. Six volunteers participated in the study, and were required to lift a weight with squat and stoop techniques, with two types of loading at $1,7 \mathrm{~kg}$ and $6,7 \mathrm{~kg}$. Observations were made on the rectus femoris, biceps femoris, and multifidus muscles. The results of study showed that the squat technique had higher levels of muscle activation compared to stoop technique on rectus femoris muscle. On the contrary, squat technique had lower muscle activation compared to stoop technique on biceps fermoris muscle. Meanwhile, both techniques squat and stoop had the same level of muscle activation on multifidus muscle. Conclusion, squat and stoop lifting techniques had the same opportunities to use.
\end{abstract}

Keywords: Electromyography, squat, stoop, muscles activation, musculoskeletal.

\section{Pendahuluan}

Penanganan bahan secara manual atau manual materials handling (MMH) mengacu pada pelaksanaan pekerjaan yang melibatkan manusia sebagai sumber tenaga. MMH tediri dari mengangkat, menurunkan, mendorong, menarik, membawa dan memegang. Selama mengangkat bahan, seseorang memindahkan benda dari satu lokasi ke lokasi lainnya dengan melawan gravitasi. Ada tiga ketinggian dalam pekerjaan mengangkat dan menurunkan bahan yaitu dari lantai sampai ke lutut, lutut ke bahu, dari bahu ke jangkauan lainnya. Pekerjaan mengangkat melibatkan berat, bentuk, ukuran benda dan postur pekerja.

Postur adalah konfigurasi tubuh untuk memulai suatu aktivitas. Perbedaan bahan yang ditangani memerlukan postur tubuh yang berbeda pula. Benda dapat diangkat dengan tiga cara yaitu teknik squat (punggung lurus), teknik stoop (kaki lurus), dan semi-squat atau disebut juga free style yaitu kombinasi antara teknik squat dan teknik stoop (Ayoub and Mital [1], Oborne [17]). Untuk memprediksi gaya-gaya otot yang timbul akibat variasi cara mengangkat digunakan alat Electromyography (EMG).

\footnotetext{
$1^{1^{*}}$ Fakultas Teknik, Jurusan Teknik Mesin, Universitas Udayana. Kampus Bukit Jimbaran, Bali 80361, Indonesia

Email: waysurat@yahoo.com

* Penulis korespondensi
}

EMG adalah teknik untuk mengevaluasi dan mencatat signal aktivasi otot. EMG mendeteksi potensial listrik yang dihasilkan oleh sel-sel otot ketika sel-sel tersebut sedang berkontraksi. EMG memegang peranan yang sangat penting dalam memahami fungsi otot. Analisis ergonomi sering menggunakan EMG ketika membandingkan tekanan otot skeletal yang berhubungan dengan berbagai macam sikap kerja, postur, layout tempat kerja, dan desain peralatan (Marras [14], Kumar and Mital [11]). Banyak penelitian di bidang ergonomi dan kesehatan kerja yang berkaitan dengan $\mathrm{MMH}$, perancangan tempat kerja, biomekanik, dan pekerjaan yang sifatnya repetitif dianalisis menggunakan EMG (Gant et al. [5], Nou et al. [16], Kumashiro [12], Khoiri [9], Theado et al. [21]).

Mengangkat dan menurunkan benda telah lama dipandang sebagai kegiatan yang berkaitan dengan faktor risiko tinggi berkembangnya keluhan tulang belakang (Staker [19], Kingma et al. [10], O’Brien and O'Sullivan [18], Lee et al. [13], Mawston and Boocock [15]). Usaha untuk meminimumkan cidera tulang belakang dan mengurangi biaya kompensasi telah dilakukan dengan memberi instruksi cara mengangkat beban yang aman. Pencegahan risiko cidera dalam mengangkat beban menjadi sangat penting untuk menjaga kesehatan pekerja di industri. Para praktisi merekomendasikan bahwa teknik squat dianggap lebih aman dibandingkan teknik stoop (Kingma et al. [10], Bazrgari et al. [2]). Teknik stoop telah dihindari karena diyakini mengakibatkan resiko cidera yang lebih besar selama meng- 
angkat beban. Beberapa hasil penelitian mendukung hipotesis ini.

Bazrgari et al. [2] mengemukakan bahwa momen neto, gaya otot, dan gaya kompresi internal atau gaya geser lebih besar pada teknik stoop dibandingkan pada teknik squat. Jarak angkat berpengaruh pada sudut tulang belakang dan secara signifikan lebih rendah pada teknik squat dibandingkan teknik stoop ketika mengangkat benda yang berada 10-40 cm di depan kaki (Gill et al. [6]). Tekanan intradiskal pada lumbar lebih tinggi pada teknik stoop dibandingkan pada teknik squat (Grandjean [7]).

Sementara teknik stoop umum diketahui sebagai teknik mengangkat yang tidak benar dan selalu dihindari, akan tetapi beberapa hasil penelitian justru mendukung penggunaan teknik stoop (Straker [20], Wang et al. [22]). Banyak pekerja lebih suka teknik stoop karena lebih mudah dilakukan, konsumsi energi lebih rendah pada pekerjaan yang berulang, dan kesetimbangan lebih baik (Bazrgari et al. [2], Straker [20]). Denyut nadi kerja juga ditemukan lebih tinggi pada teknik squat, dibandingkan pada teknik stoop, sementara pada teknik semi-squat denyut nadi berada diantara squat dan stoop (Wang et al. [22], Straker [20]). Selain itu teknik squat tidak selalu dapat dilakukan karena masih tergantung pada posisi angkat dan ukuran benda yang diangkat. Kelihatannya masih kontroversi, karena tidak satupun dari kedua teknik ini memiliki bukti-bukti yang kuat yang menyatakan satu teknik lebih baik dari yang lainnya (Dieen et al. [4], Straker [20], O'Brien and O'Sullivan [18], Bazrgari et al. [2], Mawston and Boocock [15]).

Tujuan penelitian ini adalah untuk mempelajari dan membandingkan teknik squat dan teknik stoop dalam mengangkat beban melalui analisis tingkat aktivasi otot menggunakan alat electromyography.

\section{Metode Penelitian}

\section{Subyek}

Enam relawan laki-laki dengan umur antara 20-30 tahun berpartisipasi sebagai subjek pada penelitian ini. Semua subjek tidak pernah mengalami keluhan tulang belakang, atau kondisi patologi pada lutut. Teknik squat ditandai dengan posisi awal sudut lutut $45^{\circ}$ dan punggung ke depan dengan sudut lebih kecil dari 30 (Wang et al. [22], Straker [19]). Pemegangan dilakukan dengan menekuk kaki, sementara punggung dijaga tetap lurus dan aksi pengangkatan utama terjadi sebagai hasil melurusnya lutut yang dikenal dengan mengangkat dengan kaki (leg lift) seperti ditunjukkan pada pada Gambar 1.

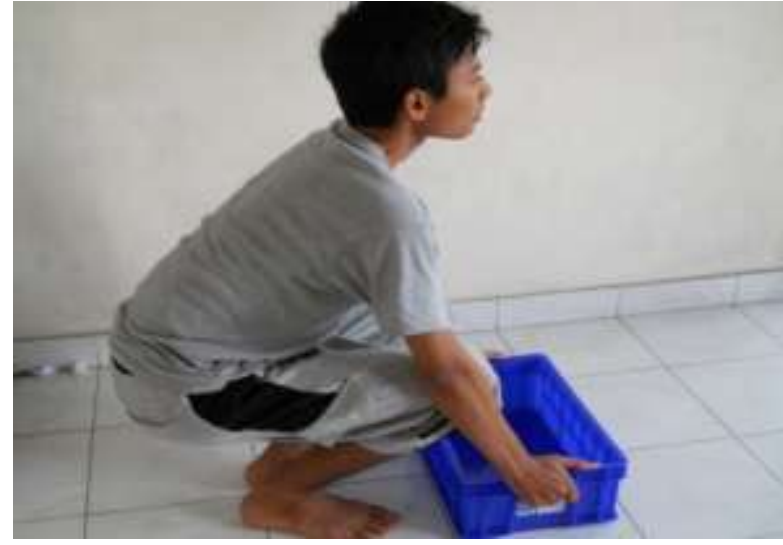

Gambar1. Postur mengangkat dengan teknik squat

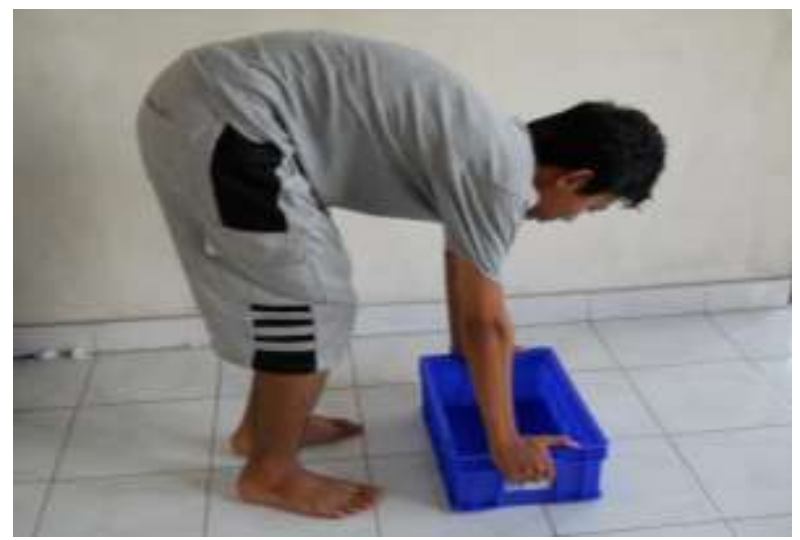

Gambar 2. Postur mengangkat dengan teknik stoop

Teknik stoop dicirikan dengan posisi awal punggung membungkuk sekitar 90 dan sudut lutut lebih besar dari 35 (Wang et al. [22], Straker [19]). Lutut dijaga lurus, sementara pinggang dan lengan ke arah depan untuk memegang benda. Pengangkatan dilakukan dengan meluruskan daerah lumbar tulang belakang dan sendi pinggul, cara ini dikenal dengan mengakat dengan pinggang (back lift) seperti ditunjukkan pada Gambar 2.

\section{Instrumentasi}

Pengukuran aktivasi otot menggunakan Surface Electromyography (SEMG) dengan sistem telemetri. Unit peralatan terdiri dari komputer, perekam, penerima, unit transmisi, amplifier, elektrode, dan kabel-kabel penghubung, seperti ditunjukkan pada Gambar 3.

\section{Prosedur Penelitian}

Sebelum pemasangan elektrode, lokasi kulit tempat menempelnya elektrode digosok dengan amplas khusus kemudian dibersihkan dengan alkohol untuk mengurangi tahanan kulit agar terjadi kontak permukaan yang baik. Selanjutnya dilakukan pengambilan data maximum voluntary contraction 

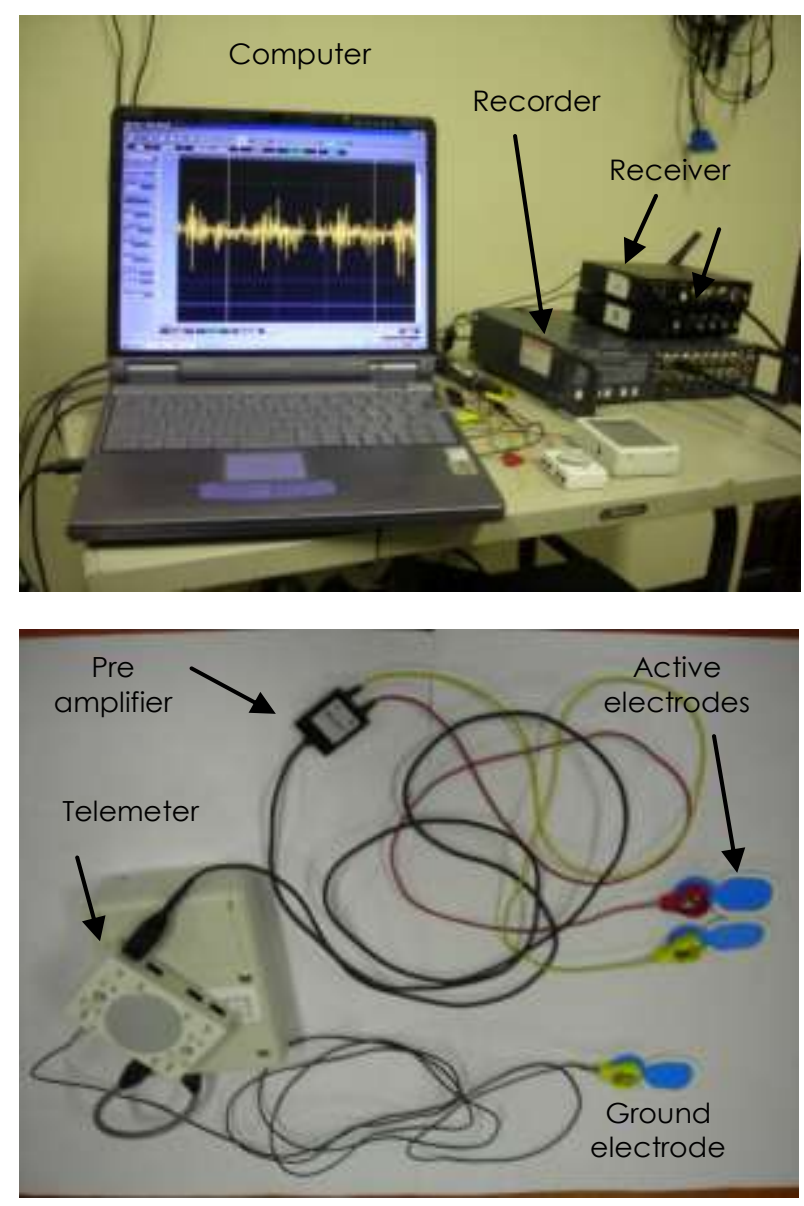

Gambar 3. Surface electromyography

(MVC) terhadap otot yang menjadi sasaran penelitian dalam hal ini adalah otot multifidus, otot rectus femoris, dan otot biceps femoris. Ketiga jenis otot ini terpapar saat melakukan gerakan mengangkat beban baik dengan teknik squat maupun dengan teknik stoop. Subjek diinstruksikan memegang kotak pada pegangan yang ada pada kedua sisinya secara simetris. Kotak yang dipakai berdimensi $39 \mathrm{~cm}$ x 27 cm x $23 \mathrm{~cm}$ (panjang x lebar x tinggi). Kotak diletakkan $10 \mathrm{~cm}$ di depan ibu jari kaki, sehingga kotak tidak menyentuh kaki ketika diangkat. Subjek melaksanakan angkatan dengan teknik squat dan stoop dari lantai sampai setinggi lutut dalam waktu 5 detik. Percobaan dilakukan dengan dua variasi pembebanan yaitu beban dengan berat $1,7 \mathrm{~kg}$ yang merupakan berat kotak dalam keadaan kosong, dan beban dengan berat $6,7 \mathrm{~kg}$, yaitu berat kotak ditambah berat piringan baja $5 \mathrm{~kg}$. Sinyal EMG direkam dan diolah menggunakan fungsi root mean square (RMS). Setiap aktivasi otot dinormalisasikan terhadap hasil percobaan MVC-nya.

\section{Hasil dan Pembahasan}

Data pengukuran tingkat aktivasi masing-masing otot target telah dinormalisasikan terhadap MVCnya. Hasil pengukuran untuk beban angkat $1,7 \mathrm{~kg}$ disajikan dalam Tabel 1, dan untuk beban angkat 6,7 kg disajikan dalam Tabel 2.

Mengangkat beban dengan teknik squat menghasilkan tingkat aktivasi otot lebih tinggi dibandingkan dengan teknik stoop pada otot rectus femoris, baik pada beban kategori ringan 1,7 kg (Tabel 1), maupun pada beban kategori sedang 6,7 kg (Tabel 2).

Tabel 1. Data tingkat aktivasi otot pada beban angkat $1,7 \mathrm{~kg}$

\begin{tabular}{ccccccc}
\hline & \multicolumn{3}{c}{ Teknik squat (\% MVC) } & \multicolumn{3}{c}{ Teknik stoop (\% MVC) } \\
\cline { 2 - 6 } No & Rectus femoris & Biceps femoris & Multifidus & Rectus femoris & Biceps femoris & Multifidus \\
\hline 1 & 51,00 & 22,00 & 60,00 & 5,00 & 50,00 & 80,00 \\
2 & 49,00 & 30,00 & 75,00 & 8,00 & 58,00 & 60,00 \\
3 & 41,00 & 38,00 & 64,00 & 7,00 & 52,00 & 65,00 \\
4 & 21,00 & 23,00 & 56,00 & 5,00 & 44,00 & 55,00 \\
5 & 24,00 & 47,00 & 55,00 & 8,00 & 46,00 & 58,00 \\
6 & 32,00 & 72,00 & 56,00 & 8,00 & 55,00 & 59,00 \\
Rerata & 36,33 & 38,66 & 61,00 & 6,83 & 50,80 & 62,80 \\
SD & 12,67 & 18,86 & 7,64 & 1,47 & 5,30 & 9,02 \\
\hline
\end{tabular}

Tabel 2. Data tingkat aktivasi otot pada beban angkat $6,7 \mathrm{~kg}$

\begin{tabular}{ccccccc}
\hline & \multicolumn{3}{c}{ Teknik squat (\%MVC) } & \multicolumn{3}{c}{ Teknik stoop (\%MVC) } \\
\cline { 2 - 6 } No & Rectus femoris & Biceps femoris & Multifidus & Rectus femoris & Biceps femoris & Multifidus \\
\hline 1 & 70,00 & 33,00 & 72,00 & 12,00 & 70,00 & 80,00 \\
2 & 52,00 & 42,00 & 75,00 & 2,80 & 68,00 & 64,00 \\
3 & 60,00 & 18,00 & 77,00 & 4,20 & 70,00 & 62,00 \\
4 & 42,00 & 55,00 & 78,00 & 8,00 & 80,00 & 84,00 \\
5 & 43,00 & 70,00 & 74,00 & 4,50 & 60,00 & 61,00 \\
6 & 34,00 & 25,00 & 68,00 & 11,00 & 50,00 & 56,00 \\
Rerata & 50,10 & 40,50 & 74,00 & 7,08 & 66,33 & 67,80 \\
SD & 13,21 & 19,41 & 3,63 & 3,83 & 10,23 & 11,35 \\
\hline
\end{tabular}




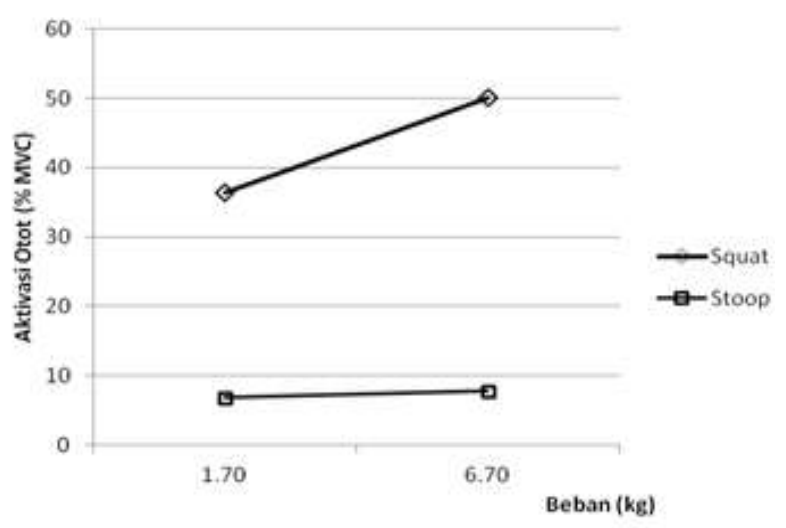

Gambar 4. Aktivasi otot rectus femoris

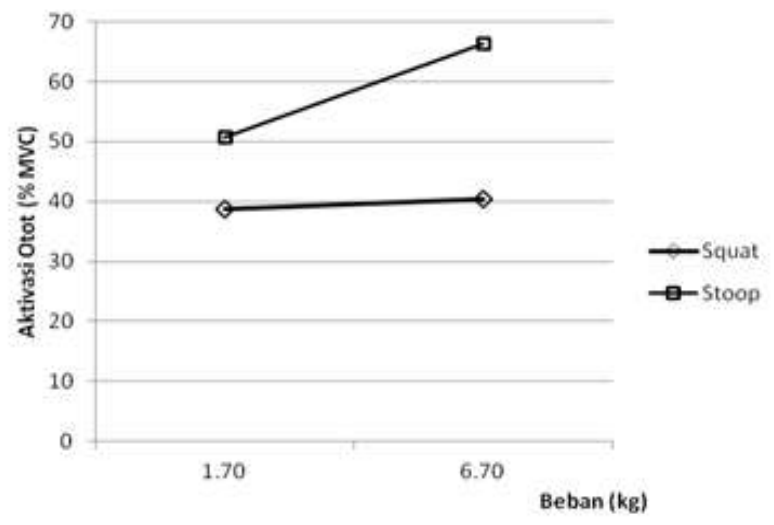

Gambar 5. Aktivasi otot biceps femoris

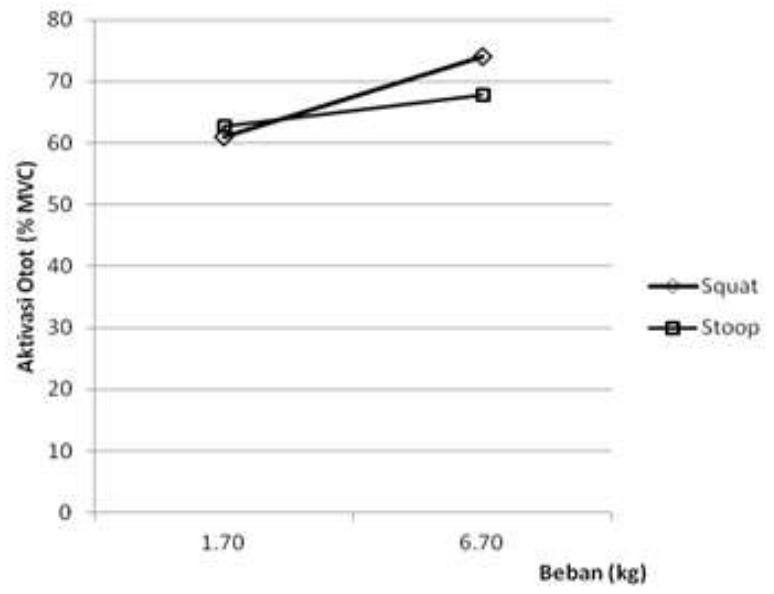

Gambar 6. Aktivasi otot multifidus

Sebaliknya teknik squat menghasilkan tingkat aktivasi otot lebih rendah dibandingkan teknik stoop pada otot biceps femoris. Pada otot multifidus tidak ada perbedaan tingkat aktivasi otot secara bermakna antara teknik squat dan teknik stoop. Ketiga jenis otot yang diteliti memiliki kecenderungan yang sama, yaitu tingkat aktivasi otot meningkat dengan betambahnya beban yang diangkat. Perbedaan teknik yang digunakan pada saat mengangkat beban, memberikan hasil aktivasi otot yang berbeda pula.

\section{Otot Rectus Femoris}

Otot rectus femoris merupakan bagian dari kelompok otot quadriceps. Rerata tingkat aktivasi otot rectus femoris untuk beban angkat $1,7 \mathrm{~kg}$ dengan teknik squat $36,33 \pm 12,67$, dan dengan teknik stoop $6,83 \pm 1,47$, nilai ini berbeda bermakna. Untuk beban angkat $6,7 \mathrm{~kg}$ dengan teknik squat $50,10 \pm 13,21$ dan dengan teknik stoop $7,08 \pm 3,83$, perbedaan ini bermakna. Secara grafik hubungan antara tingkat aktivasi otot rectus femoris terhadap beban yang diangkat ditunjukkan pada Gambar 4 . Gradien peningkatan aktivasi otot pada teknik squat lebih besar dibandingkan pada teknik stoop yang cendrung datar, artinya penambahan beban yang kecil saja akan mengakibatkan aktivasi otot sangat tinggi pada teknik squat.

Teknik squat menghasilkan aktivasi otot sebesar $50 \%$ MVC, dan dengan teknik stoop menghasilkan $7 \%$ MVC pada otot rectus femoris, untuk beban angkat $6,7 \mathrm{~kg}$. Tingkat aktivasi otot yang lebih tinggi akan menyebabkan otot lebih cepat mengalami kelelahan. Kelelahan otot dikaitan dengan menurunnya kekuatan dan kapasitas kerja otot skeletal, dan berpotensi meningkatnya risiko cidera (Hassanlouei et al. [8]). Dengan demikian teknik squat akan mengakibatkan otot rectus femoris lebih cepat mengalami kelelahan dibandingkan teknik stoop. Straker [20] menyatakan bahwa teknik squat membebani lutut lebih besar dan lebih melelahkan dibandingkan teknik stoop pada otot quadriceps, dan oleh sebab itu teknik stoop lebih disukai.

\section{Otot Biceps Femoris}

Otot biceps femoris merupakan bagian dari kelompok otot hamstrings. Tingkat aktivasi otot biceps femoris untuk beban angkat $1,7 \mathrm{~kg}$ dengan teknik squat 38,66 $\pm 18,86$, dan dengan teknik stoop $50,80 \pm 5,30$, nilai ini berbeda tidak bermakna. Untuk beban angkat $6,7 \mathrm{~kg}$ dengan teknik squat 40,50 $\pm 19,41$ dan dengan teknik stoop 66,33 $\pm 10,23$, nilai ini berbeda bermakna. Hubungan tingkat aktivasi otot biceps femoris dengan beban yang diangkat ditunjukkan pada Gambar 5. Gradien peningkatan pada teknik stoop lebih besar dibandingkan pada teknik squat yang cendrung datar, artinya penambahan beban sedikit saja, teknik stoop akan meningkatkan aktivasi otot yang lebih besar.

Teknik squat menghasilkan aktivasi otot sebesar 40\% MVC, dan dengan teknik stoop menghasilkan $66 \%$ MVC pada otot biceps fermoris untuk beban angkat $6,7 \mathrm{~kg}$. Dari data ini teknik stoop akan menyebabkan otot biceps fermoris lebih cepat mengalami kelelahan dibandingkan teknik squat. Straker [20] menyatakan teknik stoop mengakibatkan akti- 
vasi otot semitendinousis dan biceps fermoris lebih besar dibandingkan teknik squat, sehingga teknik squat lebih disukai.

\section{Otot Multifidus}

Tingkat aktivasi otot multifidus untuk beban angkat $1,7 \mathrm{~kg}$ dengan teknik squat $61 \pm 7,64$, dan dengan teknik stoop $62,80 \pm 9,20$, perbedaan ini tidak bermakna. Untuk beban angkat $6,7 \mathrm{~kg}$ dengan squat $74,00 \pm 3,63$ dan dengan stoop $67,80 \pm 11,35$, perbedaan ini juga tidak bermakna. Hubungan tingkat aktivasi otot multifidus dengan beban yang diangkat ditunjukkan pada Gambar 6. Gradien peningkatan pada teknik squat relatif lebih besar dibandingkan pada teknik stoop.

Kedua teknik mengangkat, baik squat maupun stoop, menghasilkan aktivasi otot yang sama pada otot multifidus (lumbar region), dengan kisaran $61 \%$ - 63\% MVC untuk beban angkat $1,7 \mathrm{~kg}$, dan meningkat menjadi 68\% - 74\% MVC untuk beban angkat 6,7kg. Delitto and Rose [3] melaporkan terjadi peningkatan aktivasi otot erector spinai (lumbar region) secara linear dengan bertambahnya beban ketika mengangkat dengan teknik squat. Analisis berdasarkan momen dan gaya yang bekerja pada tulang belakang diperoleh hasil yang sama untuk teknik squat dan stoop (Straker [20]). Akan tetapi menurut Dieen et al. [4] momen neto dan gaya kompresi lebih tinggi pada squat. Gaya geser pada lumbar jauh lebih rendah pada teknik squat (Dieen et al. [4], Straker [20]).

Berdasarkan pembahasan dan kajian pustaka di atas, terlihat hasil yang kontradiksi antara penggunaan teknik squat dan teknik stoop. Pada penelitian ini teknik squat menghasilkan tingkat aktivasi otot lebih tinggi dibandingkan dengan teknik stoop pada otot rectus femoris, berarti penggunaan teknik squat harus dihindari karena otot lebih mudah mengalami kelelahan dan risiko cidera. Sebaliknya teknik squat menghasilkan tingkat aktivasi otot lebih rendah dibandingkan teknik stoop pada otot biceps femoris, yang berarti teknik stoop harus dihindari. Sementara itu pada otot multifidus tidak ada perbedaan aktivasi otot secara bermakna antara teknik squat dan teknik stoop, yang berarti memiliki peluang yang sama untuk digunakan. Kondisi ini memberi pemahaman bahwa ada kompromi antara teknik squat dan teknik stoop, karena tak ada yang tanpa risiko.

Bazrgari et al. [2] melaporkan gaya internal berupa gaya tekan dan gaya geser lebih besar pada stoop dibandingkan pada squat, sehingga dianjurkan menggunakan teknik squat. Beban tulang belakang bagian atas (thoracic spine) meningkat selama mengangkat dengan teknik squat, dibandingkan dengan teknik stoop, sebaliknya beban tulang belakang bagian bawah (lumbar spine) berkurang selama squat; kondisi ini menandakan adanya kompromi antara mengangkat dengan teknik squat dan teknik stoop karena kedua-duanya memiliki risiko (Lee et al. [13]). Sebagai hasil kompromi Wang et al. [22] merekomendasikan untuk mengangkat beban berat disarankan menggunakan teknik squat, dan untuk beban ringan menggunakan teknik stoop.

\section{Simpulan}

Teknik squat dan teknik stoop memiliki peluang yang sama untuk digunakan dalam megangkat beban, trutama beban ringan sampai dengan beban sedang. Untuk mengangkat beban yang berat disarankan menggunakan teknik squat.

\section{Ucapan Terima Kasih}

Penulis mengucapkan terimakasih kepada Direktorat Jenderal Pendidikan Tinggi Republik Indonesia atas dukungan finansialnya. Ucapan terima kasih juga disampaikan kepada Professor Masaharu Kumashiro, Ketua Department of Ergonomics, Institute of Industrial Ecological Sciences, UOEH Japan, atas bimbingannya.

\section{Daftar Pustaka}

1. Ayoub, M. M., and Mital, A., Manual Materials Handling, Taylor \& Francis Publishers, London, 1989.

2. Bazrgari, B., Shirazi-Adl, A., and Arjmand, N., Analysis of Squat and Stoop Dynamic Lifting: Muscle Forces and Internal Spinal Loads, Journal of Eur Spine, 16, 2007, pp. 687-699.

3. Delitto, R. S., and Rose, S. J., An Electromyographic Analysis of Two Techniques for Squat Lifting and Lowering, Journal of Physical Therapy, 72, 1992, pp. 438-448.

4. Dieen, J. H. V., Hoozemans, M. J. M. V., and Toussaint, H. M. V., A Review of Biomechanical Studies on Stoop and Squat Lifting, Proceedings of the Human Factors and Ergonomics Society Annual Meeting, 44, 2000, pp. 643-646.

5. Gant, L., Fethke, N., and Gerr, F., Spectral Analysis of Root-Mean-Square Processed Surface Electromyography Data as a Measure of Repetitive Muscular Exertion, Proceedings of the Human Factors and Ergonomics Society Annual Meeting, 56, 2012, pp.1140-1144.

6. Gill, K. P., Bennett, S. J., Savelsbergh, G. J. P., and van Dieen, J. H., Regional Changes in Spine Posture at Lift Outset with Changes in Lift Distance and Lift Style, Journal of Eur Spine, 32, 2007, pp. 1599-1604. 
7. Grandjean, E., Fitting the Task to the Man, Taylor \& Francis Publishers, London, 2000.

8. Hassanlouei, H., Nielsen, L. A., Kersting, U. G., Falla, D., Effect of Exercise-Induced Fatigue on Postural Control of the Knee, Jornal of Electromyography and Kinesiology, 22(3), 2012, pp. 342-347.

9. Khoiri, M., Tinjauan Aplikasi Elektromiografi dalam Ergonomi. Seminar Nasional IV SDM Teknologi Nuklir, Yogyakarta, 2008, pp. 217223.

10. Kingma, I., Boch, T., Bruins, L., and van Dieen, J. H., Foot Positioning Instruction, Initial Vertical Load Position and Lifting Technique: Effects on Low Back Loading, Journal of Ergonomics, 47, 2004, pp. 1365-1385.

11. Kumar, S., and Mital, A., Electromyography in Ergonomics, Taylor \& Francis Publisher, London, 1996.

12. Kumashiro, M., Evaluation of Human Work: Practical Measurement of Psychophysiological Functions for Determining Workloads, Taylor \& Francis Publishers, London, 2005, pp. 605-627.

13. Lee, P. J., Lee, E. L., and Hayes, W. C., Biomechanical Trade-Offs in Manual Material Handling: Some Tasks Reduce Lumbar Loading but Increase Thoracic Loading, Proceedings of the Human Factors and Ergonomics Society Annual Meeting, 56, 2012, pp.1192-1195.

14. Marras, W., Selected Topics in Surface Electromyography for Use in the Occupational Setting: Expert Perspectives, U.S. Department of Health and Human Services, National Institute for Occupational Safety and Health, 1992.
15. Mawston, G. A., and Boocock, M. G., The Effect of Lumbar Posture on Spinal Loading and the Function of the Erector Spinae: Implications for Exercise and Vocational Rehabilitation, Journal of Physiotherapy, 40(3), 2012, pp. 135-140.

16. Nou, D., Miller, B. J., and Fathallah, F. A., Low Back Muscle Fatigue Measurements of Cyclic and Prolonged Stooped Work, Proceedings of the Human Factors and Ergonomics Society Annual Meeting, 56, 2012, pp.1996-1200.

17. Oborne, D. J., Ergonomics at Work, John Wiley \& Sons, 1988.

18. O'Brien, A., and O'Sullivan, L., A Biomechanical, Physiological and Psychophysical Study of the Squat, Stoop, and Semi-squat Lifting Techniques, Proceedings of the Irish Ergonomics Society Annual Conference, 2005, pp. 24-31.

19. Straker, L., Evidence to Support Using Squat, Semi-squat and Stoop Techniques to Lift Lowlying Objects, Journal of Industrial Ergonomics, 31, 2003a, pp. 149-160.

20. Straker, L. M., A Review of Research on Techniques for Lifting Low-lying Objects: 2. Evidence for a Correct Technique, IOS Press, 20, 2003b, pp. 83-96.

21. Theado, E. W., Knapik, G. G., Marras, W. S., Modification of an EMG-Assisted Biomechanical Model for Pushing and Pulling, International Journal of Industrial Ergonomics, 37(11-12), 2007, pp. 825-831.

22. Wang, Z., Wu, L., Sun, J., He, L., Wang, S., and Yang, L., Squat, Stop, or Semi-Squat: A Comparative Experiment on Lifting Technique, Journal of Huazhong University of Sciences and Technology, 32(4), 2012, pp. 630-636. 